\title{
Therapeutic Plasma Exchange in Pediatric Kidney Disease: 23-year Experience at the Severance Children's Hospital in Korea
}

\author{
Sun MiHer, M.D. ${ }^{1}$ \\ Keum Hwa Lee, M.D. 1,2,3 \\ JiHong Kim, M.D.,Ph.D. ${ }^{4}$ \\ Jae Seung Lee, M.D., Ph.D. ${ }^{1}$ \\ Pyung KilKim, M.D., Ph.D. ${ }^{1}$ \\ Jaell Shin, M.D., Ph.D. ${ }^{1,2,3}$ \\ Department of Pediatrics ${ }^{1}$, Yonsei \\ University College of Medicine, \\ Seoul, Korea, Division of Pediatric \\ Nephrology' ${ }^{2}$, Severance Children's \\ Hospital,Seoul, Korea, Institute of \\ Kidney Disease Research ${ }^{3}$, Yonsei \\ University College of Medicine, Seoul, \\ Korea, Department of Pediatrics, \\ Gangnam Severance Hospital, Yonsei \\ University College of \\ Medicine, Seoul, Korea \\ Corresponding author: \\ Jaell Shin, M.D., Ph.D. \\ Department of Pediatrics, Yonsei \\ University College of Medicine, 50-1 \\ Yonsei-ro, Seodaemun-gu, Seoul 03722, \\ Korea \\ Tel: +82-2-2228-2050 \\ Fax: +82-2-393-9118 \\ E-mail:SHINJI@yuhs.ac
}

Received: 30 June 2017

Revised: 18 September 2017

Accepted: 20 September 2017

This is an open-access article distributed under the terms of the Creative Commons Attribution Non-Commercial License (http:// creativecommons.org/licenses/by-nc/4.0/) which permits unrestricted non-commercial use, distribution, and reproduction in any medium, provided the original work is properly cited.

Copyright (C) 2017The Korean Society of Pediatric Nephrology
Purpose: The American Society for Apheresis provides clinical guidelines for therapeutic apheresis in adults, but there are no guidelines for children. This study aimed to analyze the effect of therapeutic plasma exchange (TPE) in pediatric patients with various kidney diseases in Korea.

Methods: We retrospectively reviewed the data of 16 children (up to 18 years of age) who were admitted to Severance Children's Hospital with refractory kidney disease. All patients received TPE between 1994 and 2016. Clinical and laboratory characteristics such as age, weight, sex, change in blood urea nitrogen (BUN), and creatinine level before and after TPE, and complications afterTPE were analyzed. Results: The mean age and weight of the 16 patients at the time of TPE was $11.3 \pm$ 4.0 years and $34.6 \pm 17.5 \mathrm{~kg}$, respectively. The BUN level was $35.4 \mathrm{mg} / \mathrm{dL}$ before TPE and significantly decreased to $21.5 \mathrm{mg} / \mathrm{dL}(P=0.025)$ at 1 week and $20.5 \mathrm{mg} / \mathrm{dL}(P=$ 0.01 ) at 1 month after TPE. The creatinine level significantly decreased from 1.20 $\mathrm{mg} / \mathrm{dL}$ before TPE to $0.90 \mathrm{mg} / \mathrm{dL}(P=0.02)$ at 1 week after TPE. Four complications (hypovolemia, anemia, hypocalcemia, and thrombocytopenia) were reported, but were not fatal.

Conclusion: Our findings suggest that TPE is an effective therapeutic modality in children with refractory kidney disease and can be indicated for the treatment of various kidney diseases.

Key words: Blood urea nitrogen, Creatinine, Kidney disease, Pediatrics, Plasma exchange

\section{Introduction}

Therapeutic plasma exchange (TPE) is a treatment modality to remove circulating pathologic substances from the plasma and replace them with a substitution fluid (e.g., albumin or plasma) ${ }^{1,2)}$. TPE has been applied in various diseases such as neurological diseases (e.g., myasthenia gravis, Guillain-Barré syndrome), hematological disorders (e.g., thrombotic thrombocytopenic purpura, hemolytic uremic syndrome), metabolic disorders (e.g., inborn errors of metabolism, homozygous familial hypercholesterolemia), and kidney diseases (e.g., the renal transplant candidate, antibody mediated renal allograft rejection, recurrent focal segmental glomerulosclerosis (FSGS) after renal transplantation, antineutrophil cytoplasmic antibodies and antiglomerular 
basement membrane antibody-associated rapidly progressing glomerulonephritis, and atypical hemolytic uremic syndrome (aHUS)) $)^{3)}$.

The first reported plasmapheresis was performed at Johns Hopkins University in $1914^{4}$. Decades later, the first plasma exchange in a human was conducted in a patient with Waldenstrom's macroglobulinemia in $1960^{5}$. The TPE technique was developed gradually and the clinical application of TPE has expanded remarkably. The American Society for Apheresis (ASFA) guideline provides the clinical indications for the evidence-based use of therapeutic apheresis in adult studies ${ }^{6)}$. In addition, TPE is a widely recognized therapeutic option in pediatric patients as well as in adults. However, there is no guideline for children, especially those with kidney disease.

In a PubMed search, there were about 30 papers regarding TPE in pediatric patients with kidney disease ${ }^{7-9)}$. There were particularly few studies about TPE in children with kidney disease in Korea ${ }^{10)}$. Therefore, further study of TPE in pediatric patients with kidney diseases is warranted.

TPE is an important treatment modality for children with renal and other immune-mediated diseases ${ }^{3)}$. For the continued development of TPE as an optimal treatment modality in pediatric patients, accurate data are required based on long-term experience.

The purpose of this study was to review the data of pediatric patients with kidney diseases treated with TPE at a single institution over the last 23 years in terms of etiologies, characteristics, complications, and clinical outcomes.

\section{Materials and methods}

\section{Patients}

We retrospectively reviewed the data of children (up to 18 years of age) who underwent TPE between 1994 and 2016 in Severance Children's Hospital. We identified 37 children admitted to Severance Children's Hospital who had undergone TPE during the study period. Among them, there were 19 patients (51.3\%) with kidney diseases, 9 patients (24.3\%) with neurologic diseases, and 7 patients (18.9\%) with hepatic diseases. Three of the patients with kidney diseases were excluded due to missing data; thus, 16 patients ( 2 male and 14 female) with kidney diseases were included in this study.

\section{Data collection}

The patients' medical records were obtained from the nephrology department and data including patients' demographic and clinical characteristics (age, sex, body weight, indication for TPE, treatment, prognosis), main features of the TPE procedures (frequency of TPE, site of initial vascular access, type of replacement fluid, plasma volume), and complications were analyzed. Blood urea nitrogen $(\mathrm{BUN})$, serum creatinine, $\mathrm{C} 3, \mathrm{C} 4$, proteinuria and serum albumin levels were measured before and after TPE, and the values were compared.

\section{TPE procedure}

Effective volume was calculated as effective plasma volume $(\mathrm{mL})=$ body weight $\times 70 \mathrm{~mL} / \mathrm{kg} \times(1$-hematocrit $)$. TPE was performed every other day, and a total 1-1.5 volume of plasma was exchanged, depending on patients' weight and hematocrit. The replacement fluids were albumin $4 \%$ and/ or fresh frozen plasma (FFP) according to the indication for TPE. A double-lumen hemodialysis central venous catheter was inserted through the jugular, subclavian, or femoral vein according to the patient's vascular anatomy. TPE was performed using COBE Spectra (Thermo BCT Inc., Lakewood, CO, USA) by centrifugation.

\section{Statistical analysis}

Continuous variables are expressed as the mean \pm standard deviation or medians with ranges. Data were analyzed with a paired t-test. All statistical analyses were performed by using SPSS software (version 22.0, IBM Corporation, Armonk, NY, USA) and a $P$ value less than 0.05 was considered statistically significant.

\section{Results}

\section{Demographic data}

From April 1994 to February 2016 a total of 16 patients with kidney diseases who were younger than 18 years underwent TPE. The clinical characteristics of the patients are shown in Table 1. There were two male and 14 female patients. The mean age at onset was $11.3 \pm 4.0$ years and the 
body weight was $34.6 \pm 17.5 \mathrm{~kg}$.

\section{Therapeutic effects of TPE}

In this study, three patients underwent more than one TPE session, resulting in a total of 19 TPE sessions. Some patients responded very well to the first TPE session, but subsequently needed another course of TPE for the same or a different indication.

In the present study, the etiologies for TPE were lupus nephritis (9 patients), FSGS (4 patients), Denys-Drash syndrome (1 patient), microscopic polyarteritis (1 patient), and aHUS (1 patient). The patients were divided into four groups depending on the reason for TPE: refractory (12 patients), recurrent (2 patients), rejection (1 patient), and others (4 patients) (Table 1). The refractory group comprised patients who had no response to steroid, cyclophosphamide, methylprednisolone, azathioprine, and cyclosporine treatment. The recurrent group comprised patients who presented recurrence after kidney transplantation, and the rejection groups comprised patients who presented acute rejection after kidney transplantation.

The comparison between laboratory values (BUN and serum creatinine) before and after TPE is shown in Table 1. BUN level at 1 week significantly decreased from 35.4 $\mathrm{mg} / \mathrm{dL}$ to $21.5 \mathrm{mg} / \mathrm{dL}(P=0.025)$ and creatinine level significantly decreased from $1.20 \mathrm{mg} / \mathrm{dL}$ to $0.90 \mathrm{mg} / \mathrm{dL}(P=0.02)$. BUN level at 1 month after TPE significantly decreased from $35.4 \mathrm{mg} / \mathrm{dL}$ to $20.5 \mathrm{mg} / \mathrm{dL}$ ( $P=0.01$ ) (Table 4 ).

Also, in order to investigate the TPE effect in patients with lupus nephritis, C3, C4 and proteinuria values before and after TPE are shown in Table 2. In addition, Anti-DNA $\mathrm{Ab}$ titer was investigated for TPE effect evaluation in lupus nephritis (Table 2). Among the children with lupus nephritis, six patients were found to have increased anti-DNA $\mathrm{Ab}$ titer before TPE. In addition, anti-DNA Ab titer decreased in 3 patients (patient 2, 5, 9) after TPE, and there was no difference in 5 patients (patient $1,3,4,6,8$ ) after TPE (Table 2).

And serum albumin and proteinuria values before and after TPE are shown in Table 3 to reveal the TPE effect in

Table 1. The Characteristics and Therapeutic Effects of Patients who Underwent TPE

\begin{tabular}{|c|c|c|c|c|c|c|c|c|c|c|}
\hline Patient & Diagnosis & Sex & $\begin{array}{l}\text { Age } \\
\text { (year) }\end{array}$ & $\begin{array}{l}\text { Weight } \\
(\mathrm{kg})\end{array}$ & Year & Treatment pre-TPE & Reason for TPE & $\begin{array}{l}\text { Pre-TPE } \\
\text { BUN/Cr } \\
(\mathrm{mg} / \mathrm{dL})\end{array}$ & $\begin{array}{c}1 \text { weeks f/u } \\
\text { BUN/Cr } \\
(\mathrm{mg} / \mathrm{dL})\end{array}$ & $\begin{array}{c}1 \text { month f/u } \\
\text { BUN/Cr } \\
(\mathrm{mg} / \mathrm{dL})\end{array}$ \\
\hline 1 & Lupus nephritis & $\mathrm{F}$ & 15 & 50.6 & 1994 & $P$ & Refractory & $14.5 / 0.5$ & $15.1 / 0.8$ & $11.0 / 0.6$ \\
\hline 2 & Lupus nephritis & $\mathrm{F}$ & 12 & 34 & 1994 & $P ; M P ; C Y C$ & Refractory & $17 / 0.5$ & $17.7 / 0.6$ & $11.5 / 0.7$ \\
\hline 3 & Lupus nephritis & $\mathrm{F}$ & 15 & 59 & 1997 & $P ; M P$ & Refractory & $13.5 / 0.6$ & $8.2 / 0.8$ & $6.0 / 0.4$ \\
\hline 4 & Lupus nephritis & $F$ & 14 & 54.5 & 1997 & MP & Refractory & $7.3 / 0.7$ & $10 / 0.6$ & $8.0 / 0.8$ \\
\hline 5 & Lupus nephritis & M & 12 & 35.5 & 1998 & - & TTP & $37 / 1.1$ & $32.3 / 1.1$ & $11.7 / 0.7$ \\
\hline 6 & Lupus nephritis & $\mathrm{F}$ & 14 & 52.5 & 2000 & $P ; C s A ; M P ; C Y C$ & Refractory & $35.4 / 2.1$ & $21.5 / 1$ & $28.5 / 0.9$ \\
\hline 7 & Lupus nephritis & $\mathrm{F}$ & 8 & NA & 2001 & MP & Refractory & $84 / 3.2$ & $33 / 1.3$ & Expire \\
\hline 8 & Lupus nephritis & $\mathrm{F}$ & 11 & NA & 2001 & $P ; M P$ & Refractory & $28 / 0.8$ & $9.3 / 1.3$ & $21.8 / 0.7$ \\
\hline $9-1$ & Lupus nephritis & $\mathrm{F}$ & 13 & 48 & 2005 & $\mathrm{P} ; \mathrm{CYC}$ & Refractory & $71.5 / 6$ & $63.5 / 5.8$ & $73 / 7.5$ \\
\hline $9-2$ & & & 18 & 45.5 & 2011 & KT & Rejection & $43 / 2.26$ & $25.5 / 1.79$ & $26.4 / 1.78$ \\
\hline $10-1$ & FSGS & $\mathrm{F}$ & 10 & 26 & 1997 & $P ; C s A ; K T$ & Recur & $49.5 / 1.2$ & 30/0.9 & $36 / 0.8$ \\
\hline $10-2$ & & & 12 & 35 & 1999 & CSA;P & Refractory & $53.5 / 1.8$ & $38 / 1.5$ & NA \\
\hline $11-1$ & FSGS & $\mathrm{F}$ & 3 & 13.5 & 2001 & $P ; C S A ; M P ; C Y C$ & Refractory & $14 / 0.3$ & $46 / 0.5$ & 21.5/0.4 \\
\hline $11-2$ & & & 14 & 33 & 2013 & CYC; KT & Recur & $35.9 / 1.2$ & $11.9 / 0.49$ & $24.7 / 0.65$ \\
\hline 12 & FSGS & $\mathrm{F}$ & 16 & 54 & 2008 & $P ; C S A ; M P$ & Refractory & $34.2 / 2.2$ & $24.4 / 0.9$ & 18.9/1.5 \\
\hline 13 & FSGS & $\mathrm{F}$ & 7 & 15 & 2012 & P & TTP & $23 / 0.58$ & $20.7 / 0.57$ & $9.9 / 0.64$ \\
\hline 14 & Denys-Drash syndrome & M & 4 & 15.4 & 2011 & Anti-hypertensive drug; PD & ABO-incompatible & $76.7 / 9.33$ & $88 / 6.92$ & $20.5 / 0.66$ \\
\hline 15 & ANCA-associated RPGN & $\mathrm{F}$ & 7 & 7 & 2001 & MP; CYC & Refractory & $117 / 2.3$ & 20.8/1.6 & 23/1.3 \\
\hline 16 & Atypical HUS & $\mathrm{F}$ & 10 & 10 & 2008 & CRRT & Atypical HUS & $87.1 / 6.3$ & $24.5 / 2.5$ & $8.8 / 0.7$ \\
\hline
\end{tabular}

Abbreviations: ANCA, anti-neutrophil cytoplasmic antibodies; CRRT, continuous renal replacement therapy; CSA, cyclosporine; CYC, cyclophosphamide; FSGS, focal segmental glomerulosclerosis; HUS, hemolytic-uremic syndrome; KT, kidney transplantation; F, female; M, male; MP, methylprednisolone; NA, not available; P, oral steroid; PD, peritoneal dialysis; RPGN, rapidly progressive glomerulonephritis; TPE, therapeutic plasma exchange; TTP, thrombotic thrombocytopenic purpura; BUN, blood urea nitrogen; Cr, serum creatinine. 
Table 2. Therapeutic Effects of Lupus Nephritis Patients who Underwent TPE

\begin{tabular}{|c|c|c|c|c|c|c|c|c|c|c|}
\hline Patient & Diagnosis & Sex & $\begin{array}{l}\text { Age } \\
\text { (year) }\end{array}$ & $\begin{array}{l}\text { Reason } \\
\text { for TPE }\end{array}$ & $\begin{array}{l}\text { Pre-TPE Urine } \\
\text { Protein } \\
\text { (positive on stick) }\end{array}$ & $\begin{array}{l}\text { One month f/u } \\
\text { Urine Protein } \\
\text { (postive on stick) }\end{array}$ & $\begin{array}{c}\text { Pre-TPE } \\
\text { (3/C4 } \\
(\mathrm{mg} / \mathrm{dL})\end{array}$ & $\begin{array}{c}1 \text { month f/u } \\
\text { C3/C4 } \\
(\mathrm{mg} / \mathrm{dL})\end{array}$ & $\begin{array}{c}\text { Pre-TPE } \\
\text { Anti-DNA Ab } \\
\text { titer }\end{array}$ & $\begin{array}{l}1 \text { month f/u } \\
\text { Anti-DNA Ab } \\
\text { titer }\end{array}$ \\
\hline 1 & Lupus nephritis & $\mathrm{F}$ & 15 & Refractory & $3+$ & $1+$ & $42 / 8$ & $74 / 13$ & $1: 160,+$ & $1: 160,+$ \\
\hline 2 & Lupus nephritis & F & 12 & Refractory & - & - & $41 / 6$ & $64 / 7$ & $1: 160,+$ & $1: 40,+$ \\
\hline 3 & Lupus nephritis & $\mathrm{F}$ & 15 & Refractory & $3+$ & $2+$ & $37 / 4$ & $38 / 5$ & $1: 40,+$ & $1: 40,+$ \\
\hline 4 & Lupus nephritis & $F$ & 14 & Refractory & - & - & $35 / 12$ & $27 / 7$ & $1: 160,+$ & $1: 160,+$ \\
\hline 5 & Lupus nephritis & M & 12 & TTP & $3+$ & $3+$ & $16 / 12$ & $72 / 21.4$ & $1: 160,+$ & - \\
\hline 6 & Lupus nephritis & $\mathrm{F}$ & 14 & Refractory & $3+$ & $3+$ & $90 / 19$ & NA & - & - \\
\hline 7 & Lupus nephritis & F & 8 & Refractory & NA & NA & NA & NA & - & NA \\
\hline 8 & Lupus nephritis & F & 11 & Refractory & $3+$ & $1+$ & $20 / 1.4$ & $30 / 2.4$ & - & - \\
\hline $9-1$ & Lupus nephritis & $\mathrm{F}$ & 13 & Refractory & $3+$ & - & $47 / 4.6$ & $53 / 11$ & $1: 40,+$ & - \\
\hline $9-2$ & Lupus nephritis & & 18 & Rejection & - & - & $75 / 8.2$ & NA & NA & NA \\
\hline
\end{tabular}

C3 reference range ( $90-180 \mathrm{mg} / \mathrm{dL})$, C4 reference range (10-40 mg/dL).

Abbreviations: F, female; M, male; NA, not available; TPE, therapeutic plasma exchange; TTP, thrombotic thrombocytopenic purpura.

Table 3. Therapeutic Effects of FSGS Patients who Underwent TPE

\begin{tabular}{|c|c|c|c|c|c|c|c|c|}
\hline Patient & Diagnosis & Sex & $\begin{array}{l}\text { Age } \\
\text { (year) }\end{array}$ & Reason for TPE & $\begin{array}{l}\text { Pre-TPE Urine Protein } \\
\text { (postive on stick) }\end{array}$ & $\begin{array}{l}\text { One month f/u Urine } \\
\text { Protein (postive on stick) }\end{array}$ & $\begin{array}{c}\text { Pre-TPE } \\
\text { Albumin (g/dL) }\end{array}$ & $\begin{array}{c}1 \text { month } \mathrm{f} / \mathrm{u} \\
\text { Albumin }(\mathrm{g} / \mathrm{dL})\end{array}$ \\
\hline $10-1$ & FSGS & $F$ & 10 & Recur & $3+$ & $2+$ & 2.8 & 3.5 \\
\hline $10-2$ & & & 12 & Refractory & $2+$ & - & 3.9 & 4.1 \\
\hline $11-1$ & FSGS & F & 3 & Refractory & $3+$ & $3+$ & 1.6 & 2.8 \\
\hline $11-2$ & & & 14 & Recur & $3+$ & $3+$ & 1.8 & 2.7 \\
\hline 12 & FSGS & $\mathrm{F}$ & 16 & Refractory & $3+$ & $3+$ & 1.1 & 2.4 \\
\hline 13 & FSGS & $\mathrm{F}$ & 7 & TTP & - & - & 4.4 & 2.9 \\
\hline
\end{tabular}

Abbreviations: F, female; FSGS, focal segmental glomerulosclerosis; NA, not available; TPE, therapeutic plasma exchange; TTP, thrombotic thrombocytopenic purpura.

Table 4. Laboratory Findings before and after TPE (at 1 Week and 1 Month)

\begin{tabular}{lccccc}
\hline & Before TPE & After 1 week $^{*}$ & $P$-value & After 1 month & $P$-value \\
\hline BUN (mg/dL) & $35.4(17-49.5)$ & $21.5(15.1-30.0)$ & 0.02 & $20.5(11.0-24.7)$ & 0.01 \\
Creatinine $(\mathrm{mg} / \mathrm{dL})$ & $1.20(0.65-2.28)$ & $0.90(0.60-1.60)$ & 0.02 & $0.70(0.65-0.90)$ & 0.11 \\
\hline
\end{tabular}

*1 week immediately after TPE.

${ }^{\dagger} 1$ month immediately after TPE.

Abbreviations: TPE, therapeutic plasma exchange; BUN, blood urea nitrogen.

Table 5. Laboratory Findings and Proteinuria before and after TPE in Lupus Nephritis Patients

\begin{tabular}{lccc}
\hline & Before TPE & After 1 month* & $P$-value \\
\hline C3 (mg/dL) & $34 \pm 11.6$ & $51.1 \pm 19.7$ & 0.082 \\
C4 (mg/dL) & $6.9 \pm 4.0$ & $9.5 \pm 6.3$ & 0.18 \\
Proteinuria (postive on stick) & $2+$ & $1+$ & 0.052 \\
\hline
\end{tabular}

*1 month immediately after TPE.

Abbreviations: TPE, therapeutic plasma exchange;BUN, blood urea nitrogen; Cr, serum creatinine.

FSGS patients. In patients with lupus nephritis, $\mathrm{C} 3$ level and C4 level at 1 month after TPE increased from $34 \mathrm{mg} / \mathrm{dL}$ to $51.1 \mathrm{mg} / \mathrm{dL}(P=0.082)$ and from $6.9 \mathrm{mg} / \mathrm{dL}$ to $9.5 \mathrm{mg} / \mathrm{dL}(P=$ $0.18)$, respectively. However, these results were not statistic-
Table 6. Laboratory Findings and Proteinuria before and after TPE in FSGS Patients

\begin{tabular}{lccc}
\hline & Before TPE & After 1 month* & $P$-value \\
\hline Albumin (g/dL) & $2.6 \pm 1.3$ & $3.1 \pm 0.6$ & 0.322 \\
Proteinuria (postive on stick) & $2+$ & $2+$ & 0.203 \\
\hline
\end{tabular}

*1 month immediately after TPE.

Abbreviations: FSGS, focal segmental glomerulosclerosis; TPE, therapeutic plasma exchange.

ally significant compared to those in BUN and creatinine (Table 5). In patients with FSGS, albumin at 1 month after TPE increased from $2.6 \mathrm{~g} / \mathrm{dL}$ to $3.1 \mathrm{~g} / \mathrm{dL}(P=0.322)$, but was not statistically significant (Table 6). 


\section{Clinical outcomes}

Among the 16 patients, 3 patients received kidney transplantation and 3 patients were treated with hemodialysis due to end-stage renal disease (ESRD). A complete response was defined as a patient who was treated after TPE with no more following up. A partial response was defined as patients without proteinuria after TPE or other treatments and patients with well-controlled proteinuria (proteinuria $1+$ ). Complete response was observed in 1 patient (patient 16), and partial response was observed in 5 patients (patient $3,5,6,11$ and 13). Three of nine patients with lupus nephritis and two of four patients with FSGS showed partial response. One patient was eventually expired (patient 7).

\section{TPE procedure and complications}

The 16 patients underwent a total of 104 sessions. The average frequency of TPE per each case was $5.5 \pm 3.8$ sessions, and the procedures were carried out using a central venous catheter. The type of vascular access was chosen based on the patient's vascular anatomy and the most common site was the subclavian vein ( 8 cases), followed by the internal jugular vein ( 5 cases). The replacement fluids were $4 \%$ albumin ( 9 cases, $47 \%$ ) or FFP (5 cases, $26 \%$ ) according to the patients' general condition. Four complications were reported for the 104 TPE sessions (hypovolemia, anemia, hypocalcemia, and thrombocytopenia) (Table 7).

\section{Discussion}

Although TPE has been increasingly used as a first-line therapy in the last few decades, there is a lack of research about TPE in pediatric kidney diseases. Therefore, the aim of this study was to analyze the therapeutic effect of TPE in pediatric kidney diseases ${ }^{11,12}$.

In 1980, plasmapheresis was introduced in Korea, and the first procedure was performed in Severance Hospital in a patient with membranous proliferative glomerulonephritis in 1981. TPE non-selectively removes pathogenic substances or replaces a deficient factor, as in systemic thrombotic microangiopathy ${ }^{3}$. The ASFA Special Issue, 7th edition, published in 2016 classifies disorders into four categories. Category I is accepted as first-line therapy, and category II is accepted as supportive or adjunctive therapy. However, category III is not established, and category IV is ineffective or harmful ${ }^{6}$. There are few published reports

Table 7.TPE Procedure and Complications

\begin{tabular}{|c|c|c|c|c|c|}
\hline Patient & Diagnosis & Number of sessions & Replacement solution & Vascular access & Complication \\
\hline 1 & Lupus nephritis & 3 & $4 \%$ albumin & Subclavian vein & - \\
\hline 2 & Lupus nephritis & 3 & $4 \%$ albumin & Subclavian vein & - \\
\hline 3 & Lupus nephritis & 5 & NA & NA & - \\
\hline 4 & Lupus nephritis & 5 & NA & Internal J.V. & Hypovolemia \\
\hline 5 & Lupus nephritis & 3 & $4 \%$ albumin & Internal J.V. & - \\
\hline 6 & Lupus nephritis & 3 & NA & NA & - \\
\hline 7 & Lupus nephritis & 3 & $4 \%$ albumin & NA & - \\
\hline 8 & Lupus nephritis & 6 & NA & NA & - \\
\hline $9-1$ & Lupus nephritis & 10 & FFP & Internal J.V. & - \\
\hline $9-2$ & & 5 & $4 \%$ albumin & Subclavian vein & - \\
\hline $10-1$ & FSGS & 15 & $4 \%$ albumin & Subclavian vein & Anemia \\
\hline $10-2$ & & 5 & FFP & Subclavian vein & - \\
\hline $11-1$ & FSGS & 14 & $4 \%$ albumin & Subclavian vein & - \\
\hline $11-2$ & & 3 & FFP & Subclavian vein & Hypocalcemia \\
\hline 12 & FSGS & 9 & $4 \%$ albumin & Internal J.V. & - \\
\hline 13 & FSGS & 3 & FFP & Femoral vein & - \\
\hline 14 & Denys-Drash syndrome & 2 & $4 \%$ albumin & Internal J.V. & - \\
\hline 15 & Microscopic polyarteritis & 4 & NA & NA & - \\
\hline 16 & Atypical HUS & 3 & FFP & Subclavian vein & Thrombocytopenia \\
\hline
\end{tabular}


about TPE conducted in pediatric patients, thus, the indications for TPE in children are based on those in adults.

Song et al. showed that the most common indications of TPE in the nationwide survey on Korea were myasthenia gravis (15.3\%), followed by thrombotic thrombocytopenic purpura (TTP) (14.5\%), and HUS (9.7\%) ${ }^{13)}$. Volder et al. showed that TPE indications in pediatric and adolescent patients from the World Apheresis registry data were neurological diseases (33\%) and renal diseases (17\%). Paglialonga et al. reported that the indications of TPE in European pediatric nephrology units were FSGS (16.4\%) and HUS/ $\operatorname{TTP}(17.9 \%)^{8,14)}$. In addition, Reddy et al. reported that the etiologies for TPE were aHUS (75\%), anti-glomerular basement membrane disease (12.5\%), lupus nephritis (6.25\%), and microscopic polyangiitis $(6.25 \%)$ (Table 8$)^{15)}$. In our single-center study, the indications of TPE in pediatric patients with kidney diseases were lupus nephritis (52.6\%), FSGS (31.6\%), and HUS/TTP (15.8\%).

TPE in lupus nephritis is classified as Category IV according to the ASFA. Lewis et al. showed that TPE in combination with prednisolone and cyclophosphamide is not as effective for the treatment of lupus nephritis as compared with prednisolone and cyclophosphamide alone ${ }^{6)}$. On the contrary, Li et al. reported that lupus nephritis patients with thrombotic microangiopathy who underwent TPE had a significantly higher rate of remission than those who did not undergo $\mathrm{TPE}^{16,17)}$. In this study, TPE in a lupus nephritis patient with thrombotic TTP (patient 5) had a clinical effect. Currently, the patient has no proteinuria and is regularly followed up at the outpatient clinic. Among the remaining lupus nephritis patients who underwent TPE, no children have progressed to ESRD, 3 patients (patient 3 , patient 5, and patient 6) are undergoing outpatient observation and 3 patients (patient 1 , patient 2 , and patient 8 ) failed to attend follow up visits in our clinic. In addition, 1 patient (patient 4) moved to another hospital after improvement, and 1 patient (patient 7 ) died due to exacerbation of pneumonia. While TPE for lupus nephritis is classified as Category IV according to the ASFA, the results of the present study show that TPE has some effect on lupus nephritis.

In a review article by Ponticelli et al., 70\% of recurrent FSGS children who underwent TPE presented complete or partial remission, and according to Straatmann et al., early TPE was $100 \%$ effective in patients with recurrent FSGS ${ }^{18}$, ${ }^{19)}$. In this study, the patient (patient 11) with recurrent FSGS who underwent TPE 6 days after kidney transplantation presented complete remission. However, the patient (patient 10) with recurrent FSGS who underwent TPE 4 months after kidney transplantation progressed to ESRD and was on hemodialysis. Therefore, early TPE in patients with recurrent FSGS may be important to improve the prognosis.

The ASFA guideline classifies TTP for ABO incompatible

Table 8. Comparisons of Our Study with Previous Studies Regarding Therapeutic Effects of TPE

\begin{tabular}{|c|c|c|c|}
\hline & Paglialonga, et a $\left.\right|^{8)}$ & Reddy, et al ${ }^{15)}$ & Ours \\
\hline Publication year & 2015 (Europe) & 2015 (India) & - (Korea) \\
\hline Study period & 2012 & 2009-2013 & 1994-2016 \\
\hline No. of Patients & 67 (M 29/F 38) & 16 (M 10/F 6) & 16 (M 2/F 14) \\
\hline Age & $\leq 18 \mathrm{yrs}$ & $5-18$ yrs & $\leq 18 \mathrm{yrs}$ \\
\hline \multirow[t]{4}{*}{ Etiologies } & HUS/TTP 17.9\% & aHUS 75\% & Lupus nephritis 56\% \\
\hline & FSGS $16.4 \%$ & anti-GBM 12.5\% & FSGS $25 \%$ \\
\hline & Desensitization of rTx 13.4\% & Lupus nephritis 6.25\% & Desensitization of rTx $6.3 \%$ \\
\hline & & MPA $6.25 \%$ & \\
\hline No. of procedurs & 6 & 11 & 5.2 \\
\hline \multirow[t]{3}{*}{ Replacement fluid } & Albumin (46.2\%) & NA & Albumin (50\%) \\
\hline & Plasma (31.3\%) & & FFP (25\%) \\
\hline & Albumin+plasma (11.9\%) & & \\
\hline \multirow[t]{2}{*}{ Complications } & Total $6.9 \%$ & Cath.related inf. 18.8\% & Total $3.8 \%$ \\
\hline & & Allergic reaction $12.5 \%$ & \\
\hline
\end{tabular}

Abbreviations: aHUS, atypical hemolytic uremic syndrome; anti-GBM, anti-glomerular basement membrane disease; F, female; FFP, fresh frozen plasma; M, male; MPA, microscopic polyangiitis; No., number; rTx, renal transplantation; FSGS, focal segmental glomerulosclerosis; ;TTP, thrombotic thrombocytopenic purpura; NA, not available. 
renal transplantation as Category I. In this study, TPE was performed as first-line treatment for TTP (patient 9 and patient 13) and $\mathrm{ABO}$ incompatible renal transplantation (patient 14) and resulted in BUN reduction, creatinine reduction, and clinical effectiveness.

Paglialonga et al. showed that TPE complications in pediatric nephrology units occurred in 51 of 738 sessions (6.9 $\%)$. According to Volker et al., complications were reported in 4 out of 50 sessions (8\%), and in this study, complications were found in 4 out of 104 sessions $(3.8 \%)^{8,20)}$. None of the complications led to death, and all were resolved. Although TPE is a safe and effective therapeutic tool, Pamela et al. reported that among patients hospitalized with ASFA Category I or II disease, only $13.4 \%$ and $9.3 \%$ underwent TPE, respectively ${ }^{211}$. In this study, when TPE was performed in patients with diseases corresponding to ASFA Category I and II, TPE was clinically effective in 5 (patient 9, 11, 13, 14, and 16) of 6 patients, and only 1 patient (patient 15) was on hemodialysis due to progressed ESRD. Therefore, it is thought that TPE will be helpful as therapeutic modality in children with kidney disease.

When TPE is performed, albumin and FFP are most commonly used as replacement fluid. Regarding the advantages and disadvantages of each fluid, albumin is relatively expensive but has a lower risk of transfusion-transmitted infection. FFP maintains the activity of all blood coagulation factors but has a high risk of viral transmission and more frequent adverse reactions such as allergic reactions $^{22,23)}$. Albumin is used more than plasma due to the lower risk of allergic reactions and transmission of viral infections by plasma ${ }^{24)}$. In this study, albumin (47\%) was used more frequently than FFP (26\%). Depending on the underlying disease and the laboratory findings, the selection of appropriate replacement fluid is important.

Carter et al. reported that catheter-related complications such as catheter-related thrombosis and infection were common when TPE was used in pediatric patients ${ }^{3}$. Catheter-related complications should be considered when performing TPE in children, but these were not reported in this study. Additional considerations for the improvement of TPE outcomes in children include safe sedation in non-cooperative patients and vascular access methods.

Overall, the present study has some limitations including its retrospective design and the inclusion of a small number of patients. As TPE was used in combination with immunosuppressive therapy, the therapeutic effect of TPE alone was not evaluated in this study. In addition, insurancerelated factors may have affected the results of our study. For example, the category proposed by ASFA for certain diseases such as FSGS was changed from Category III in 2007 to Category I in 2010. In Korea, we decided to apply insurance based on the ASFA guideline, so patient 12 in this study who underwent TPE in 2008 did not receive insurance benefits ${ }^{25,26}$. If insurance was more applicable to TPE, it will be helpful in treating children with many kidney diseases.

In conclusion, TPE may be a safe and effective treatment in pediatric kidney disease patients and can be indicated for the treatment various kidney diseases. Further studies are necessary to investigate the overall results in other hospitals and institutions in Korea.

\section{Conflicts of interest}

No potential conflict of interest relevant to this article was reported.

\section{References}

1. Ward DM. Conventional apheresis therapies: a review. J Clin Apher 2011;26:230-8.

2. Baweja S, Wiggins K, Lee D, Blair S, Fraenkel M, McMahon LP. Benefits and limitations of plasmapheresis in renal diseases: an evidence-based approach. J Artif Organs 2011;14:9-22.

3. Carter CE, Benador NM. Therapeutic plasma exchange for the treatment of pediatric renal diseases in 2013. Pediatr Nephrol 2014:29:35-50

4. Abel JJ, Rowntree LG, Turner BB. Plasma removal with return of corpuscles (plasmaphaeresis). The Journal of Pharmacology and experimental therapeutics Vol. V. No. 6, July, 1914. Transfus Sci 1990;11:166-77.

5. Schwab PJ, Fahey JL. Treatment of Waldenstrom's macroglobulinemia by plasmapheresis. N Engl J Med 1960;263:574-9.

6. Schwartz J, Padmanabhan A, Aqui N, Balogun RA, ConnellySmith L, Delaney M, et al. Guidelines on the Use of Therapeutic Apheresis in Clinical Practice-Evidence-Based Approach from the Writing Committee of the American Society for Apheresis: The Seventh Special Issue. J Clin Apher 2016;31:149-62.

7. Cleper R, Krause I, Bar Nathan N, Mor M, Dagan A, Weissman I, et 
al. Focal segmental glomerulosclerosis in pediatric kidney transplantation: 30 years' experience. Clin Transplant 2016;30:1324-31.

8. Paglialonga F, Schmitt CP, Shroff R, Vondrak K, Aufricht C, Watson $A R$, et al. Indications, technique, and outcome of therapeutic apheresis in European pediatric nephrology units. Pediatr Nephrol 2015;30:103-11.

9. Yim DK, Lee ST, Cho H. Plasmaphresis therapy for pulmonary hemorrhage in a pediatric patient with IgA nephropathy. Korean J Pediatr 2015;58:402-5.

10. Lee JH, Jeon GW, Park SE, Jin DK, Paik KH. An Experience of Therapeutic Plasma Exchange in 9 Pediatric Patients. J Korean Soc Pediatr Nephrol 2005;9:38-45.

11. Song KS, Yoon HS, Lee KW, Kim HS, Lee SY. Therapeutic Plasma Exchange (9 Cases). Korean J Clin Pathol 1983;3:11-5.

12. Kim HO, Shon ES, Song KS, Lee SS. An Evaluation of 28 Cases of Therapeutic Plasma Exchange. Korean J Clin Pathol 1988;8:45967.

13. Song EY, Kwon SW, Kim DS, Kim DW, Kim DW, Kim HO, et al. Current status of therapeutic plasma exchange in Korea. Ther Apher Dial 2004;8:97-101.

14. Witt V, Stegmayr B, Ptak J, Wikstrom B, Berlin G, Axelsson CG, et al. World apheresis registry data from 2003 to 2007, the pediatric and adolescent side of the registry. Transfus Apher Sci 2008;39: 255-60.

15. Reddy SK, Jahan A, Chaturvedi S, Agarwal I. Plasma exchange for paediatric kidney disease-indications and outcomes: a singlecentre experience. Clin Kidney J 2015;8:702-7.

16. Blum D, Blake G. Lupus-associated thrombotic thrombocytopenic purpura-like microangiopathy. World J Nephrol 2015;4:52831.

17. Li QY, Yu F, Zhou FD, Zhao MH. Plasmapheresis is associated with better renal outcomes in Lupus Nephritis patients with throm- botic microangiopathy. Medicine 2016:95:1-10.

18. Ponticelli C. Recurrence of focal segmental glomerular sclerosis (FSGS) after renal transplantation. Nephrol Dial Transplant 2010; 25:25-31.

19. Straatmann C, Kallash M, Killackey M, lorember F, Aviles D, Bamgbola $\mathrm{O}$, et al. Success with plasmapheresis treatment for recurrent focal segmental glomerulosclerosis in pediatric renal transplant recipients. Pediatr Transplant 2014;18:29-34.

20. Kara A, Turgut S, Cagli A, Sahin F, Oran E, Tunc B. Complications of therapeutic apheresis in children. Transfus Apher Sci 2013;48: 375-6.

21. Weiss PF, Klink AJ, Friedman DF, Feudtner C. Pediatric therapeutic plasma exchange indications and patterns of use in US children's hospitals. J Clin Apher 2012;27:287-94.

22. Choi GR, Choi SJ, Shin SA, Lee K, Kim S, Kim HO. A Choice and Precautions of Replacement Fluids for Therapeutic Plasma Exchange. Korean J Blood Transfus 2015;26:9-17.

23. Basic-Jukic N, Kes P, Glavas-Boras S, Brunetta B, Bubic-Filipi L, Puretic Z. Complications of therapeutic plasma exchange: experience with 4857 treatments. Ther Apher Dial 2005;9:391-5.

24. Misanovic V, Pokrajac D, Zubcevic S, Hadzimuratovic A, Rahmanovic S, Dizdar S, et al. Plasmapheresis in Pediatric Intensive Care Unit. Med Arch 2016;70:332-5.

25. Szczepiorkowski ZM, Bandarenko N, Kim HC, Linenberger ML, Marques MB, Sarode R, et al. Guidelines on the use of therapeutic apheresis in clinical practice: evidence-based approach from the Apheresis Applications Committee of the American Society for Apheresis. J Clin Apher 2007;22:106-75.

26. Szczepiorkowski ZM, Winters JL, Bandarenko N, Kim HC, Linenberger ML, Marques MB, et al. Guidelines on the use of therapeutic apheresis in clinical practice--evidence-based approach from the Apheresis Applications Committee of the American Society for Apheresis. J Clin Apher 2010;25:83-177. 